\title{
EFFECTS OF A 980-NM DIODE LASER'S ACTIVATION OF 2.5\% NAOCL AND 2\% CHLORHEXIDINE ANTIFUNGAL IRRIGATION SOLUTIONS ON CANDIDA ALBICANS BIOFILMS
}

\author{
CHITRA ISELINNI, RATNA MEIDYAWATI*, NILAKUSUMA DJAUHARIE
}

Department of Conservative Dentistry, Faculty of Dentistry, Universitas Indonesia, Jakarta, Indonesia. Email: meidyawati58@gmail.com

Received: 16 September 2017, Received and Accepted: 05 October 2017

ABSTRACT

Objective: Candida albicans is the most frequently found fungi in persistent root canal infections; it can form a biofilm and penetrate into dentinal tubules. Endodontic irrigants, such as $2.5 \%$ sodium hypochlorite $(\mathrm{NaOCl})$ and $2 \%$ chlorhexidine $(\mathrm{CHX})$, have antifungal properties, but limited penetration into dentinal tubules, which somewhat protects the $C$. albicans fungi. The use of a diode laser is an innovative approach in root canal treatments because it is able to penetrate deeper into the dentinal tubules. This study examined the effect of a 980-nm diode laser on the antifungal properties of $2.5 \% \mathrm{NaOCl}$ and $2 \% \mathrm{CHX}$ on C. albicans biofilms.

Methods: The number of $C$. albicans colonies in the biofilms was recorded after irrigation using $2.5 \% \mathrm{NaOCl}$ and $2 \% \mathrm{CHX}$. Then, the biofilms were radiated using a 980 -nm diode laser.

Results: Showed statistically significant differences between the use of the irrigants only and the use of the irrigants plus the diode laser treatment in the reduction of the $C$. albicans colonies in the biofilm.

Conclusion: Diode laser is able to activate the antifungal properties of the $2.5 \% \mathrm{NaOCl}$ and $2 \% \mathrm{CHX}$ endodontic irrigants.

Keywords: Candida albicans, Diode laser, Endodontic irrigants.

(c) 2017 The Authors. Published by Innovare Academic Sciences Pvt Ltd. This is an open access article under the CC BY license (http://creativecommons. org/licenses/by/4. 0/) DOI: http://dx.doi.org/10.22159/ijap.2017.v9s2.04

\section{INTRODUCTION}

Endodontic is a branch of dentistry that focuses on the prevention, diagnosis, and treatment of dental pulp pathosis [1]. Pulp and periapical tissue infections occur when microorganisms invade the hard tissues in teeth and progress into the root canal [2]. The main objective of a root canal treatment is to eliminate microorganisms, toxins, and pathological debris from the root canal, preventing further infection to the surrounding bone [3,4]. At least 300 different microorganisms species found in root canal infections, including fungal organisms, are found in pure culture or with bacteria in primary, secondary, and persistent root canal infections. Candida albicans is the most common fungi in the oral cavity and the root canal [5]. The incidence of $C$. albicans in a healthy oral cavity is approximately 30$45 \%$, but its incidence can be as high as $95 \%$ in immune compromised individuals [6]. The prevalence of $C$. albicans in root canal infections is approximately $1-17 \%$ [7]. C. albicans is more frequently found in teeth with failed root canal treatments [8].

C. albicans dentin colonization plays an important role in persistent root canal infection, and the invasion of the C. albicans into the dentinal tubules can protect it from intracanal procedures. C. albicans is a dimorphic fungus that can alter its morphology in response to a host's attempts to fend off infection. C. albicans has hyphae morphology with a diameter around $1.9-2.6 \mu \mathrm{m}$, which suggests that it has the ability to penetrate dentinal tubules [8].

Endodontic treatment procedures rely on mechanical instrumentation, irrigants, and medicaments to disinfect the root canal [5]. Irrigants help remove microorganisms that are untouched by mechanical instrumentation [9]. The most commonly used endodontic irrigant is sodium hypochlorite $(\mathrm{NaOCl})$, which works by turning the fatty acid in microbes' cell membranes into fatty salt and glycerol, damaging the cell membranes [10]. Another endodontic irrigant is CHX. Cationic molecules from CHX bind to microbes' cell membranes, which are negatively charged, causing cell lysis. These irrigants must be in direct contact with the microorganisms to be effective, but they have limited penetration into dentinal tubules [11].

Root canal disinfection is one of the basic principles to retain tooth treated root canals in the long term. Root canal disinfection is the primary challenge in endodontic procedures, and although the use of irrigants may decrease the number of microbes in infected root canals, they do not achieve the total disinfection of entire root canal systems. Lasers are one method used to overcome this challenge because lasers can access tubular systems that irrigants cannot [5].

The antimicrobial effect of lasers depends on the dosage of the heat delivered to the target [12]. Various types of lasers, such as diode lasers, are used in dentistry. The use of diode lasers in endodontics is an innovative approach to root canal disinfection because these lasers have the ability to penetrate deeper into dentinal tubules [3]. Diode lasers have become the method of choice due to their advantages including their ease of use and relatively small size compared to other types of lasers [13].

The antimicrobial effect of lasers has been shown in previous studies. According to some studies, laser alone is not more effective than irrigants [12]. Baz et al. conducted an in vitro study on the disinfection of 60 single root canals and found that disinfection by NaOCl irrigants is significantly better than disinfection using diode lasers alone. However, disinfection with a combination of irrigants and diode lasers resulted in the greatest bactericidal effect. Therefore, the diode laser is considered as an adjunct to enhance the bactericidal effect of endodontic irrigants [10].

Kaiwar et al. found similar results when they studied the use of diode lasers combined with irrigants. This combination resulted in the highest root canal disinfection rate when compared with disinfection 
by irrigants or lasers alone. Differences in the disinfection rates were statistically significant [13].

Gerek et al. conducted an ex vivo study on 176 single-rooted teeth contaminated by bacteria and $C$. albicans. These teeth were treated using endodontic irrigants and an 810-nm diode laser. The method did not achieve complete sterilization of the root canal system, but it achieved a statistically significant decrease in the bacterial and C. albicans counts [14].

Many studies on the effect of diode lasers in root canal bacterial disinfection treatments have been conducted, but studies on the effect of $980-\mathrm{nm}$ diode lasers on fungal organisms are rare. The objective of this study is to evaluate a $980-\mathrm{nm}$ diode laser's enhancement of the antifungal properties of $2.5 \% \mathrm{NaOCl}$ and $2 \% \mathrm{CHX}$ against a C. albicans biofilm.

\section{METHODS}

This is a laboratory experimental study. C. albicans strain ATCC 10231 - provided by the Oral Biology Laboratorium in the Faculty of Dentistry, University of Indonesia - was the sample used in this study. The $C$. albicans biofilms were created on a well plate. After the biofilms were created, they were subjected to $2.5 \% \mathrm{NaOCl}$ or $2 \% \mathrm{CHX}$ solutions followed by $980-n m$ diode laser treatments. A swab of biofilm that has been treated was taken and put inside an Eppendorf tube filled with phosphate-buffered saline (PBS) solution and diluted to -6 . Each sample was cultured in a Sabouraud dextrose agar medium (SDA). The culture was incubated for $24 \mathrm{~h}$ at $37^{\circ} \mathrm{C}$

An assessment of the diode lasers' ability to enhance the antifungal properties of $2.5 \% \mathrm{NaOCl}$ and $2 \% \mathrm{CHX}$ against the $C$. albicans biofilms was completed by visually counting the colony-forming units (CFU) of $C$. albicans. The living and colonized $C$. albicans on the agar were manually counter after it was exposed to the irrigants and the 980-nm diode laser. If more colonies were formed, the $\mathrm{CFU} / \mathrm{ml}$ score increased, and the antifungal effect of the irrigant and diode laser was lower on the testing materials.

Statistical analysis was conducted using SPSS 22.0 (IBM, United States). Normality tests were conducted using the Sapiro-Wilk test, which found that the data had a normal distribution ( $p>0.05)$. Homogeneity test discovered that the data were homogenous $(p \geq 0.05)$. Therefore, data qualify for the parametric test (one-way ANOVA), which was calculated at $\mathrm{p}<0.05(\mathrm{p}=0.000)$. Finally, a post hoc Bonferroni test was conducted.

\section{RESULTS}

The mean values of the $C$. albicans count from the five experimental groups can be seen in Table 1 . The $2.5 \% \mathrm{NaOCl}$ only and $2 \%$ CHX only groups showed lower $C$. albicans counts than the biofilm $C$. albicans group. Therefore, both $2.5 \% \mathrm{NaOCl}$ and the $2 \% \mathrm{CHX}$ have antifungal properties. The $2.5 \% \mathrm{NaOCl}$ plus diode laser group had the lowest C. albicans count ( $5.67 \mathrm{CFU} / \mathrm{mL}$ ), which suggests that the use of $2.5 \%$ $\mathrm{NaOCl}$ with subsequent diode laser radiation has stronger antifungal effects than the use of $2.5 \% \mathrm{NaOCl}$ alone $(154.00 \mathrm{CFU} / \mathrm{mL})$.

The post hoc Bonferroni test results (Table 2) found a statistically significant difference in $C$. albicans count between the biofilm $C$. albicans group, $2.5 \% \mathrm{NaOCl}$ group, and the $2 \% \mathrm{CHX}$ group $(\mathrm{p}=0.001)$. No significant difference between the $2.5 \% \mathrm{NaOCl}$ group and the $2 \% \mathrm{CHX}$ group was found $(\mathrm{p}=1.000)$, which suggests that both the $2.5 \% \mathrm{NaOCl}$ and $2 \%$ CHX have similar antifungal effects on the $C$. albicans biofilm.

A statistically significant difference in C. albicans count was found between the $2.5 \% \mathrm{NaOCl}$ only group and $2.5 \% \mathrm{NaOCl}$ plus diode laser group ( $\mathrm{p}=0.001$ ). Similar results were found between the $2 \%$ CHX only group and $2 \%$ CHX plus diode laser group ( $\mathrm{p}=0.001)$. This suggests that the diode laser enhances the antifungal effects of both the $2.5 \% \mathrm{NaOCl}$ and the $2 \%$ CHX.
Table 1: The mean values of the $C$. albicans count before and after the application of the $2.5 \% \mathrm{NaOCl}$ and the $2 \% \mathrm{CHX}$ with and without diode laser radiation $(\mathrm{CFU} / \mathrm{ml})$

\begin{tabular}{|c|c|c|c|c|}
\hline \multirow[t]{2}{*}{ Experimental group } & \multirow[t]{2}{*}{$\mathbf{n}$} & \multirow[t]{2}{*}{ Mean \pm SD } & \multicolumn{2}{|l|}{$95 \%$ CI } \\
\hline & & & $\begin{array}{l}\text { Lowest } \\
\text { value }\end{array}$ & $\begin{array}{l}\text { Highest } \\
\text { value }\end{array}$ \\
\hline C. albicans biofilm & 3 & $228.00 \pm 9.00$ & 219 & 237 \\
\hline $\mathrm{NaOCl} 2.5 \%$ & 3 & $154.00 \pm 4.00$ & 150 & 158 \\
\hline CHX $2 \%$ & 3 & $151.67 \pm 22.50$ & 129 & 174 \\
\hline $\mathrm{NaOCl} 2.5 \%+$ diode laser & 3 & $5.67 \pm 3.22$ & 2 & 8 \\
\hline CHX $2 \%+$ diode laser & 3 & $6.00 \pm 1.00$ & 5 & 7 \\
\hline
\end{tabular}

C. albicans: Candida albicans, CHX: Chlorhexidine, CFU: Colony-forming units,

SD: Standard deviation, CI: Confidence interval

Table 2: The p value of the $C$. albicans count before and after the application of the $2.5 \% \mathrm{NaOCl}$ and $2 \% \mathrm{CHX}$ with and without the application of the diode laser at $980-\mathrm{nm}$ of radiation

\begin{tabular}{ll}
\hline Experimental group & p \\
\hline C. albicans biofilm versus $\mathrm{NaOCl} 2.5 \%$ & 0.001 \\
C. albicans biofilm versus $\mathrm{CHX} 2 \%$ & 0.001 \\
C. albicans biofilm versus $\mathrm{NaOCl} 2.5 \%+$ diode laser & 0.001 \\
C. albicans biofilm versus $\mathrm{CHX} 2 \%+$ diode laser & 0.001 \\
$\mathrm{NaOCl} 2.5 \%$ versus CHX 2\% & 1.000 \\
$\mathrm{NaOCl} 2.5 \%$ versus NaOCl 2.5\%+diode laser & 0.001 \\
$\mathrm{NaOCl} 2.5 \%$ versus CHX 2\%+diode laser & 0.001 \\
CHX 2\% versus NaOCl 2.5\%+diode laser & 0.001 \\
CHX 2\% versus CHX 2\%+diode laser & 0.001 \\
NaOCl 2.5\%+diode laser versus CHX 2\%+diode laser & 1.000 \\
\hline
\end{tabular}

Post hoc Bonferroni statistic test with $\mathrm{p}<0.05$. C. albicans: Candida albicans,

CHX: Chlorhexidine

\section{DISCUSSION}

The CFU counts in the $2.5 \% \mathrm{NaOCl}$ and $2 \% \mathrm{CHX}$ groups were lower than the control group, which suggests that both $2.5 \% \mathrm{NaOCl}$ and $2 \%$ CHX have antifungal properties with regard to C. albicans. Siquiraand Sen. also found that these irrigants had antifungal effects on C. albicans [8]. The $2.5 \% \mathrm{NaOCl}$ group and $2 \%$ CHX group's CFU counts had no statistically significant difference, which suggests that $2 \%$ CHXs antifungal properties are comparable to 2.5\% NaOCl's antifungal properties against the $C$. albicans biofilm. Sena et al. found similar result that both $\mathrm{NaOCl}$ and $\mathrm{CHX}$ have antifungal properties but do not differ significantly, supporting the findings of this study [15].

Gopikrishna et al. found that a $60^{\circ} \mathrm{C}$ increase in the $1.25 \% \mathrm{NaOCl}$ temperature can significantly reduce the viscosity of $\mathrm{NaOCl}$ and may influence the movement of $\mathrm{NaOCl}$ solution on root canal in clinical applications [16]. Gulsahi also found that a $37^{\circ} \mathrm{C}$ increase in the $2.5 \%$ $\mathrm{NaOCl}$ temperature can increase the effectiveness of $\mathrm{NaOCl}$ against C. albicans [17].

The use of a diode laser is an innovative approach to root canal disinfection. Diode lasers are able to create heat increasing the temperature of the irrigants [18]. An increase in the temperature of low concentrations of $\mathrm{NaOCl}$ solutions can enhance the solution's antimicrobial properties $[16,17,19]$. Table 1 summarizes a reduction in the $\mathrm{CFU}$ in the $2.5 \% \mathrm{NaOCl}$ plus diode laser radiation group when compared to the $2.5 \% \mathrm{NaOCl}$, only group. Table 2 summarizes the statistically significant difference between the two groups.

Table 1 summarizes a reduction in the CFU in the $2 \%$ CHX plus diode laser radiation group when compared with the $2 \%$ CHX only group. Table 2 summarizes the statistically significant difference between the two groups. Therefore, the use of a diode laser enhances the effect of $2 \%$ CHX on C. albicans. 
No studies or literature have been found regarding the use of a 980$\mathrm{nm}$ diode laser combined with $2 \%$ CHX against $C$. albicans the effect of changing the $2 \%$ CHX temperature in root canal disinfection. Hmud et al. found that a 980-nm diode laser can induce cavitation on a waterbased medium by the formation and implosion of water vapor. Bubble pressure from cavitation can increase the breakdown of the irrigation solution, which enhances disinfection. In the root canal, the bubble pressure can potentially destroy microorganisms' biofilms, rupture cell membranes, and to clear the smear layer and debris [20]. The $2 \%$ CHX solution is thought to create cavitation after subsequent diode laser radiation, supporting the findings of this study, which showed an increase in the antifungal properties of $2 \%$ CHX after diode laser radiation.

An explanation of the effect of a 980-nm diode laser on the C. albicans biofilm has not been discussed in previous literature. However, many studies researched the effect of diode lasers on bacteria are assumed to be applicable to C. albicans. Bago et al. and Baz et al. studied E. faecalis and concluded that diode lasers have a better effect if they are used in conjunction with endodontic irrigants $[10,12]$. Similar results were found in this study. The CFU of $C$. albicans was significantly lower in the irrigants plus diode laser groups than the irrigants only groups. Therefore, we concluded that the diode laser activates the antifungal properties of the $2.5 \% \mathrm{NaOCl}$ and the $2 \% \mathrm{CHX}$ against $C$. albicans.

\section{CONCLUSION}

This study found that the $2.5 \% \mathrm{NaOCl}$ and $2 \% \mathrm{CHX}$ endodontic irrigants have antifungal properties. The use of a diode laser in addition to the irrigants can activate the antifungal properties of the $2.5 \% \mathrm{NaOCl}$ and $2 \%$ CHX.

\section{ACKNOWLEDGMENT}

The publication of this manuscript is supported by Universitas Indonesia.

\section{REFERENCES}

1. Garg N, Garg A, editors. Introduction and scope of endodontics. In: Textbook of Endodontics. $3^{\text {rd }}$ ed. New Delhi: Jaypee Brothers Medical Publishers; 2014.

2. Mathew J, Emil J, Paulaian B, John B, Raja J, Mathew J. Viability and antibacterial efficacy of four root canal disinfection techniques evaluated using confocal laser scanning microscopy. J Conserv Dent 2014; $17: 444-8$.

3. Jonathan R, Mathew J, Suganthan P, Samuel A, John B. Comparative evaluation of the antibacterial efficacy of four different disinfection techniques in minimally instrumented experimentally infected root canals: An in vitro study. Int J Laser Dent 2013;3:49-54

4. Shenoy A, Mandava P, Bolla N, Raj S, Kurien J, Prathap MS. Antibacterial efficacy of sodium hypochlorite with a novel sonic agitation device. Indian J Dent Res 2013;24:537-41.

5. Onay EO, Alikaya C, Seker E. Evaluation of antifungal efficacy of erbium, chromium: Yttrium-scandium-gallium-garnet laser against Candida albicans. Photomed Laser Surg 2010;28 Suppl 1:S73-8.

6. Mohammadi Z, Asgary S. Antifungal activity of endodontic irrigants. Iran Endod J 2015;10:144-7.

7. Shenoy A, Nayak S, Bella N. An in vitro comparison of the antimicrobial effects of sodium dichloroisocyanurate, $\mathrm{CHX}$ and sodium hypochlorite against Enterococcus faecalis and Candida albicans. Guident 2013;6:69-74

8. Siqueira JF Jr, Sen BH. Fungi in endodontic infections. Oral Surg Oral Med Oral Pathol Oral Radiol Endod 2004;97:632-41.

9. Garg N, Garg A. Irrigation and intracanal medicaments. In: Garg N, Garg A, editors. Textbook of Endodontics. Malaysia: Unipress Publishing; 2008.

10. Baz P, Biedma B, Pinon M, Mundina B, Bahillo J, Prado R, et al. Combined sodium hypochlorite and $940 \mathrm{~nm}$ diode laser treatment against mature e.Faecalis biofilms in vitro. J Lasers Med Sci 2012;3:116-21.

11. Mehrvarzfar P, Saghiri MA, Asatourian A, Fekrazad R, Karamifar K, Eslami G, et al. Additive effect of a diode laser on the antibacterial activity of $2.5 \% \mathrm{NaOCl}, 2 \% \mathrm{CHX}$ and MTAD against Enterococcus faecalis contaminating root canals: An in vitro study. J Oral Sci 2011;53:355-60.

12. Bago I, Plecko V, Gabric Panduric D, Schauperl Z, Baraba A, Anic I. Antimicrobial efficacy of a high-power diode laser, photo-activated disinfection, conventional and sonic activated irrigation during root canal treatment. Int Endod J 2013;46:339-47.

13. Kaiwar A, Usha HL, Meena N, Ashwini P, Murthy CS. The efficiency of root canal disinfection using a diode laser: In vitro study. Indian J Dent Res 2013;24:14-8.

14. Gerek M, Asci S, Yaylali D. Ex vivo evaluation of antibacterial effects of ND: YAG and diode lasers in root canals. Biotechnol Biotechnol Equip 2010;23:2031-4.

15. Sena NT, Gomes BP, Vianna ME, Berber VB, Zaia AA, Ferraz CC, et al. In vitro antimicrobial activity of sodium hypochlorite and CHX against selected single-species biofilms. Int Endod J 2006;39:878-85.

16. Gopikrishna V, Ashok P, Kumar AP, Narayanan LL. Influence of temperature and concentration on the dynamic viscosity of sodium hypochlorite in comparison with 17\% EDTA and 2\% CHX gluconate: An in vitro study. J Conserv Dent 2014;17:57-60.

17. Gulsahi K, Tirali RE, Cehreli SB, Karahan ZC, Uzunoglu E, Sabuncuoglu B. The effect of temperature and contact time of sodium hypochlorite on human roots infected with Enterococcus faecalis and Candida albicans. Odontology 2014;102:36-41.

18. Pradhan S, Kamik R. Temperature rise on external root surface during laser endodontic therapy using $940 \mathrm{~nm}$ diode laser: An in vitro study. Int J Laser Dent 2011;1:29-35.

19. Sirtes G, Waltimo T, Schaetzle M, Zehnder M. The effects of temperature on sodium hypochlorite short-term stability, pulp dissolution capacity, and antimicrobial efficacy. J Endod 2005;31:669-71.

20. Hmud R, Kahler WA, George R, Walsh LJ. Cavitational effects in aqueous endodontic irrigants generated by near-infrared lasers. J Endod 2010;36:275-8. 